\title{
To Assess or Not to Assess: Tensions Negotiated in Six Years of Teaching Teachers about Computational Thinking
}

\author{
Daniel HICKMOTT, Elena PRIETO-RODRIGUEZ \\ School of Education, The University of Newcastle, Australia \\ e-mail:daniel.hickmott@uon.edu.au,elena.prieto@newcastle.edu.au
}

Received: September 2018

\begin{abstract}
Coding and computational thinking have recently become compulsory skills in many school systems globally. Teaching these new skills presents a challenge for many teachers. A notable example of professional development designed using Constructionist principles to address this challenge is ScratchEd. Upon reflecting on her experiences designing and running ScratchEd, Karen Brennan identified five tensions faced by professional development providers, and proposed that these tensions could be used for scrutinising and critiquing professional development. In this paper we analyse, through the lens of Brennan's tensions, the process we have followed to design, evaluate and improve professional development. We argue that while we have experienced the same tensions, the extent to which we assess learning is a new tension that extends those identified by Brennan. There are strong reasons to assess teachers' knowledge, however, quantitative measures of learning could be at odds with Constructionism: as Papert argued in Mindstorms, constructionist educators should study their learning environments as anthropologists. Consequently, we have called this new tension the tension between anthropology and assessment.
\end{abstract}

Keywords: teacher professional development; Constructionism; computational thinking; programming; pedagogical content knowledge.

\section{Introduction}

Recently, while working with a colleague to develop a joint research project proposal on teaching quality, he asserted, 'just add coding or computational thinking somewhere, it's the only way to get funds these days'. This colleague is a successful academic in the field of physical education and has what one could consider an impressive track record with funding applications. While this comment is not entirely reflective of the funding situation in the field of educational research, and admittedly was pronounced in jest, it provides an interesting insight into how prominent coding has become for education authorities worldwide. Many countries have recently introduced, or are planning 
to introduce, curricula that include the teaching of Coding and Computational Thinking throughout K-12 (Webb et al., 2016). Australia has recently introduced a Digital Technologies learning area within its new national curriculum (Falkner, Vivian, Falkner, \& Williams, 2017), England introduced a Computing Curriculum in 2014 that is mandatory for all K-6 students (Sentance \& Csizmadia, 2016), and in the United States there have been national efforts to introduce K-12 Computer Science education into all of the states (Brown \& Briggs, 2015; Fisher, 2016).

However, Coding and Computational Thinking (C\&CT) are not new to schools and there have been many attempts to bring these skills into mainstream K-12 education since the 1970s. Many of these efforts were led by constructionists, who encouraged students coding in Logo, and similar programming languages, to explore "powerful ideas", as Papert (1980, p. 138) had envisioned. The teaching of coding in Logo did not become widespread in K-12 education in the 1980s and 1990s, due to a complex mix of social, political and technical issues, and a "lack of subject-matter integration" (Agalianos, Whitty, \& Noss, 2006; Kafai \& Burke, 2013, p. 61). Papert (1987, p. 24) lamented that many researchers and educators had taken a "technocentric" view of Logo and that they had ignored many of the powerful ideas from Mindstorms (Papert, 2000).

The renewed interest in C\&CT has motivated educators and researchers to work towards fulfilling Papert's dream (Resnick, 2017), and although Seymour has recently passed away, his legacy lives on in the 21 st Century. His ideas have had a large influence on the design of Scratch, which is widely available, free and commonly used in schools (Kafai \& Burke, 2013). The Maker Movement, which encourages learners to construct digital and physical artefacts that are personally meaningful to them, has also been influenced by Papert's Constructionism (Blikstein, 2013). Despite the wide availability of free tools for learning C\&CT, there are still some major challenges that educators and researchers are facing when introducing $\mathrm{C} \& \mathrm{CT}$ in $\mathrm{K}-12$. One of the main challenges is the preparation of teachers, as C\&CT is unlikely to have been part of their K-12 or tertiary education (Falkner et al., 2017; Yadav, Sands, Good, \& Lishinki, 2018).

To overcome the challenges that the introduction of C\&CT in school curricula presents for teachers, many professional development (PD) initiatives are being developed and implemented worldwide (Garneli, Giannakos, \& Chorianopoulos, 2015). These initiatives focus on different aspects of C\&CT and typically provide a range of experiences and knowledge for teachers to take to their classrooms. While there is general consensus that content knowledge (CK) is essential in order to effectively teach, there is also general acceptance of the importance of pedagogical content knowledge (PCK), as introduced by Lee Shulman (1986). PCK is widely used in the education literature as a means of understanding the particular types of knowledge unique to teachers. This type of knowledge includes, for example, knowledge of student misconceptions about specific topics and how teachers might respond to these and knowledge of effective analogies for illustrating concepts or ideas. PCK has been studied in the context of C\&CT both in primary and secondary school settings (Angeli et al., 2016). However, while PCK is recognised as being of crucial importance for effective teaching in C\&CT (Saeli, Perrenet, Jochems, \& Zwaneveld, 2011), research about ways to understand and promote PCK in C\&CT is still in its infancy (Cooper, Grover, Guzdial, \& Simon, 2014). There are still many les- 
sons to learn about providing appropriate and effective PD to pre-service and in-service teachers (Guzdial, 2015; Yadav et al., 2018).

Interestingly, in the special issue on 'Constructionism and Creativity' of the journal Constructivist Foundations, Karen Brennan reflected, "I am often asked 'What lessons have you learned from your [PD] work?' I have to appreciate that my experiences and understandings are more aptly described as 'tensions negotiated' than 'lessons learned"' (Brennan, 2015, p. 293). In her article, she describes the tensions she has encountered when running the ScratchEd model of PD. Brennan (2015) provides examples of when these tensions have occurred in each of the PD formats and explains the approaches she has used to negotiate these tensions.

Our experiences running PD over the last six years have taught us what we thought were invaluable lessons about what effective PD is and how certain aspects of the PD can be evaluated. However, it has become that apparent our lessons learned are much more like the tensions negotiated by Brennan (2015), and that our latest lesson learned is that we have not really learned any lessons - we have just discovered ways to negotiate tensions.

In this paper, we analyse the process we followed in the past six years to design, evaluate and improve our PD through the lens of the tensions negotiated by Brennan (2015). Our analysis highlights the importance of evaluating PD and developing metrics that can help us evaluate teachers' learning during and after the PD. As we have designed the most recent PD workshops with Constructionism as a "framework for action" (DiSessa \& Cobb, 2004, p. 83), we often find that it is difficult to decide between measuring the changes of teachers' PCK and CK, and not measuring these changes. We contend this difficulty is a new tension that differs from those identified by Brennan (2015), which we call the tension between anthropology and assessment.

The idea of this paper was presented at Constructionism 2018 and published in conference proceedings.

\section{Professional Development Design}

As stated in the previous section, many PD initiatives have been established around the world to address the challenge of preparing educators for teaching C\&CT in $\mathrm{K}-12$ (Menekse, 2015). These include Massive Open Online Courses (Falkner et al., 2017), face-to-face workshops (Menekse, 2015), and the development of local hubs that provide teachers with support from peers, known as 'Master teachers' (Sentance, Humphreys, \& Dorling, 2014).

One notable example of a model of PD that has been designed to include constructionist learning experiences is ScratchEd (Brennan, 2015). Initially, Brennan (2015) developed an online community for educators to share their experiences teaching with Scratch. After the establishment of the online community, Brennan developed Scratch educator meetups that are run for three hours on a Saturday morning each month in Boston. Brennan (2015, p. 293) stated that the online community "cannot provide constructionist experiences", and, consequently, the meetups were intended to provide these 


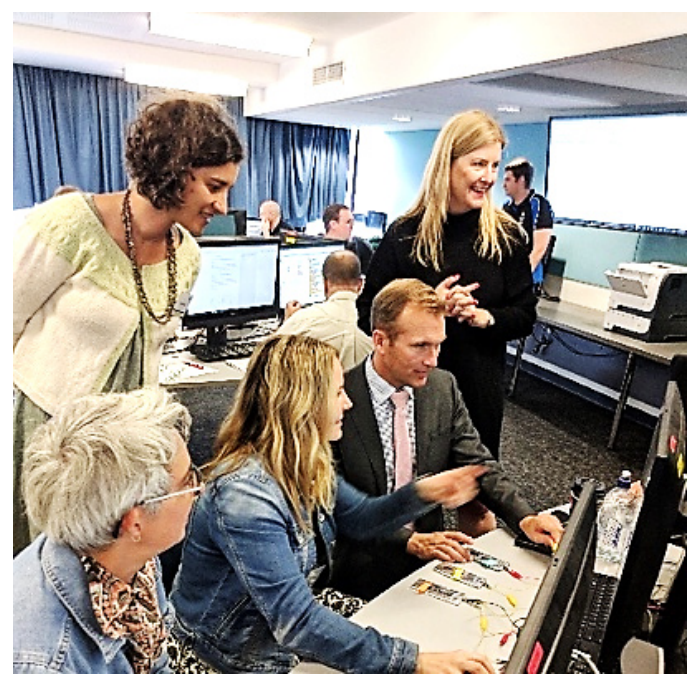

Fig. 1. Participants in 2017 workshop.

experiences. Brennan also developed an online workshop titled the Creative Computing Online Workshop (CCOW), which was available to teachers globally. The CCOW lasted six weeks and involved a variety of activities, including the development and sharing of design journals. The ScratchEd model combined these three formats of PD: the online community, monthly face-to-face meetups and the CCOW.

We have been developing and running face-to-face PD workshops at our university for six years. The main aim of the workshops has been to help prepare teachers for teaching the Australian Digital Technologies curriculum. In 2013 and 2014, the workshops were only available for High School teachers, but in 2015 we began to include Primary School teachers. These workshops have involved a variety of sessions: activities with step-by-step instructions, collaborative problem-solving exercises and lesson-planning activities, and presentations by academics and industry representatives.

The design and implementation of the workshops has evolved each year as a result of participants' feedback, which has been collected through validated surveys. As discussed later in the Tensions Negotiated section, the feedback that we received in the surveys, particularly the feedback in responses to the surveys' open-ended questions, has influenced the changes that we have made to the PD. For example, the feedback from our first workshop in 2013 indicated that there was too much theory and lectures in the sessions, which led us to begin the inclusion of more hands-on and constructionist sessions in the PD in the years that followed. We have also been informed by the general PD literature, in which there has been extensive research about what factors are present in effective PD (for example, Desimone, 2009). Unlike Brennan (2015), we have not had any online components in our PD yet, and we would argue that face-to-face PD will always be valuable and essential. The availability of face-to-face PD is particularly important for teachers who are only beginning to learn C\&CT and have low-confidence about teaching them, as argued by Sentance and Csizmadia (2017). 


\section{Tensions Negotiated}

Six years after beginning the ScratchEd project, Brennan (2015) reflected on her experiences and observations when running the different forms of PD and also analysed interviews with 30 of the teachers that participated in her PD. In her analysis, Brennan (2015, p. 294) concluded that her experiences and understandings would be best described as "tensions negotiated", rather than "lessons learned" and described the five tensions that she considered to be the most pressing. She also explained how these tensions were experienced and negotiated in the different formats of the ScratchEd model. Fig. 2 below depicts those tensions.

Like Brennan (2015), we have sought to provide constructionist learning experiences in our PD, as we believe that learning environments that are influenced by constructionist ideas should be encouraged in K-12. However, the format of the PD that we have run over the last six years has been very different to the forms of PD in the ScratchEd model. Our PD has mainly been run as two-day workshops that have been planned weeks or months beforehand and have not had an online component like the ScratchEd online community or CCOW. Like Brennan, when we have reflected on our experiences about running the workshops, we have often thought about the lessons that we have learned that could be useful for other PD providers. But, also like Brennan, we have found tensions negotiated to be a more appropriate description than lessons learned. In the conclusion of her article, Brennan argues that the tensions she identified are not specific to Scratch or her ScratchEd model, and that they could be scrutinized or critiqued by other PD providers.

In the following sections, we explain how we have experienced each of the five tensions identified by Brennan when developing and running our PD. To determine how

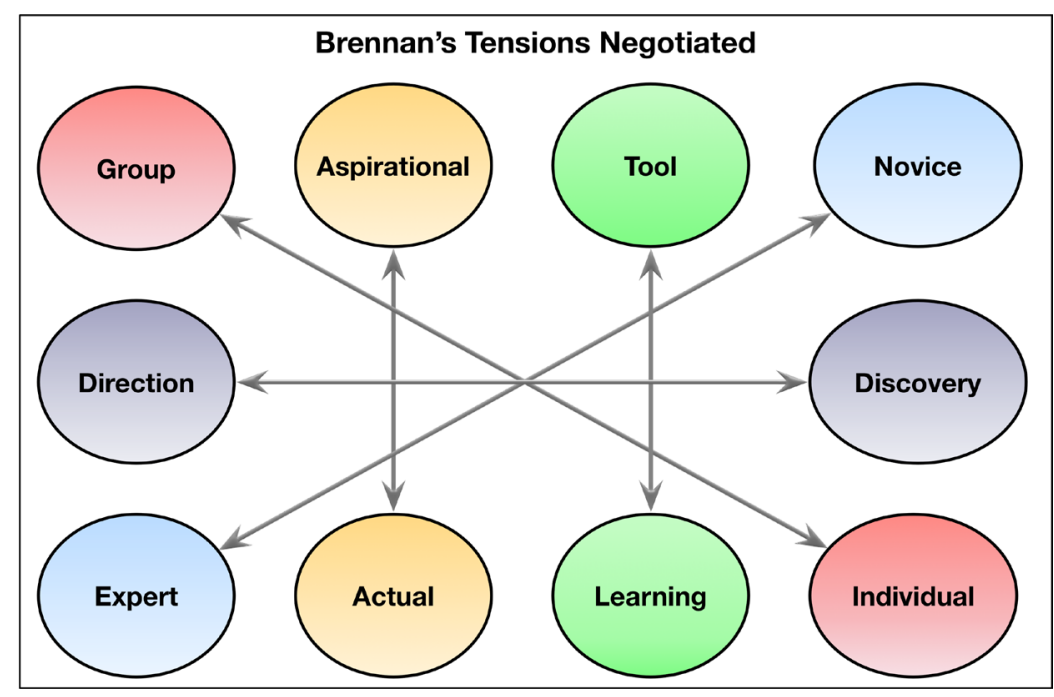

Fig. 2: Brennan (2015) tensions. 
the PD was impacted by the different tensions, we initially analysed the open-ended responses to the feedback surveys $(n=137)$ through the lens of the five tensions identified by Brennan (2015), by thematic coding the responses in NVivo 11. We also reflected on our experiences during the PD and discussed how these related to each of the different tensions. We found that teachers have been satisfied with our workshops, and some aspects have improved as a consequence of responding to feedback. However, we found that this feedback provided only insight on teachers' general satisfaction with our workshops and, to a certain extent, the classroom applicability of the PD content, but was not enough to give us a full picture of their learning. Also, our funding bodies have started to require measures of impact that go beyond self-reported self-efficacy outcomes. Consequently, we determined that we are experiencing a tension that was not identified by Brennan, which we have called the tension between anthropology and assessment, after the argument made by Papert (1980) that educators should study their learning environments as anthropologists.

\section{Tension between Tool and Learning}

The tension between tool and learning refers to balancing the PD's focus between teaching about concepts/tools (CK) and helping teachers create learning environments for students to use these concepts/tools (PCK). On one side of the tension is a focus on teaching a tool, such as Scratch, and the essential concepts needed to use and understand that tool. On the other side of the tension are the pedagogical practices and different approaches to classroom activities, such as the "creative design activities" described by Brennan (2015, p. 294).

In our workshops, we have conducted sessions with a variety of software and hardware tools and have usually focused on imparting CK. The rationale for including a variety of tools has been to make teachers aware of the many options that they have for teaching C\&CT at different levels of K-12. Each year, the teachers that have attended the workshops have taught at a variety of levels and subjects and, consequently, we always try to provide a variety of options of activities that are relevant to them.

We have often focussed on imparting $\mathrm{CK}$ in the majority of the workshop sessions because many teachers have not learned about C\&CT during their K-12 or tertiary education and much of this CK is likely to be new to them (Falkner et al., 2017; Yadav et al., 2018). Consequently, we expected that the workshops participants would not have much $\mathrm{CK}$ and that they primarily needed to acquire CK before they acquire PCK. Although the workshop sessions always involve the teaching of certain tools, we tend to have central concepts that we aim to impart in the sessions and theme the sessions accordingly. For example, we titled the session that we introduce Scratch in, "Visual Programming with Scratch". During that session we explained what visual programing is, gave examples of how visual programming can be included in $\mathrm{K}-12$, and described visual programming tools that could be used instead of Scratch.

Despite the workshop sessions having had a concept as a central theme, we have found that teachers usually responded to questions about applying the concepts learned 
during the workshops with answers about introducing the tools to their students, rather than introducing the concepts or particular pedagogical approaches in their classes. For example, in response to the question "Do you think you will you apply what you learned in the workshop? If so, what?", many teachers responded with a list of tools, such as, "Yes, makey makeys, scratch at a deeper level than I've been teaching it and sphero". Comments such as this led us to include a combination of sessions that focus on a particular concept and/or tool, and sessions that focus on particular pedagogical approaches. For example, in the 2017 Primary School workshop we introduced C\&CT concepts in Scratch in a session on the first day and then ran a session on the second day that focussed on teaching CT through design activities with the Creative Computing Curriculum guide (Brennan, Balch, \& Chung, 2014), which has activities that use Scratch.

Another difficulty encountered during our PD, which Brennan (2015) does not explicitly mention, and that we consider to be encompassed in the tension between tool and learning, is the technical issues we experienced when using certain tools. For example, we encountered technical issues when using the MIT AppInventor software with Android tablets during the "Building Mobile Apps" activity, due to the way the network was configured at our university. Although we resolved these issues quickly during the session, this troubleshooting detracted from the activity. Teachers may encounter these issues themselves with their classes, so it could be argued that it is beneficial to include instruction on how to troubleshoot these issues in PD. Despite the difficulties faced, we believe that the tools that can be difficult to use in some environments, are conducive to constructionist learning experiences. Consequently, we intend to include more instructional time that addresses the potential technical issues, so that teachers can troubleshoot these issues themselves and assist their students to troubleshoot these issues.

\section{Tension between Direction and Discovery}

The tension between direction and discovery refers to the balancing by instructors to provide guidance and resources to learners, while also allowing learners to discover resources and concepts on their own. This is similar to the "play paradox" defined by Noss and Hoyles (1996), which they used to refer to the balancing of exploration and guidance when students are learning in a microworld (for example, Logo).

When we design our PD, there are certain learning outcomes that we aim to address in each of the sessions, which align with concepts from the Australian Digital Technologies curriculum. These concepts include what Brennan and Resnick (2012) call computational concepts, which include concepts like sequencing and loops. Additionally, Primary School teachers have also been encouraged to integrate C\&CT across different subject areas (NSW Education Standards Authority, 2018), and to teach C\&CT to assist development of students' "general capabilities", for example, Literacy, Numeracy and Creative Thinking (ACARA, 2018). Our past PD workshops have been focussed on upskilling teachers' $\mathrm{CK}$ and consequently many of the sessions' planned learning outcomes have been related to the essential computational concepts from the Australian Digital Technologies curriculum. 
Brennan (2015, p. 293) designed the ScratchEd PD model with the main assumption that "teachers should have learning experiences that are comparable to their students' learning experiences". Like Brennan, we believe that if we are encouraging teachers to include constructionist learning experiences in their classes, we should be including these experiences in our PD. In recent PD workshops, we have made changes to provide more constructionist learning experiences, but we have often had to negotiate the tension between direction and discovery when designing and running the PD activities. In past evaluations of our workshops we found that teachers have enjoyed the sessions that had step-by-step exercises more than the sessions that involved self-guided activities (Prieto-Rodriguez \& Hickmott, 2016). For example, one teacher thought "it was very useful to have printed sheets to follow..." during the sessions. Conversely, some teachers responded to the surveys with suggestions to include more self-directed activities and "problems to solve with minimal guidance on how to solve them". Consequently, we have had to learn to negotiate the balance of providing different types of instruction or pedagogical approaches, as the teachers themselves are likely to do in their own classes.

In the 2016 and 2017 workshops, we began to include sessions that allowed the teachers to spend more time on self-guided exploration and play. For example, in the 2017 Primary School workshop we included a session themed around the Creative Computing curriculum guide and included the "10 Blocks" activity from that guide in the session. In the "10 Blocks" activity, learners are asked to create a Scratch program but are limited to 10 different types of blocks, which the instructor can learn about before they run the activity. These types of activities can help teachers believe that it is "...ok to not know everything as the teacher", as stated by one of the survey respondents,

Another difficulty that we have experienced designing our PD, that we consider to be encompassed within the tension between direction and discovery, is related to the limited amount of time for the PD. In most of our workshops, 20-30 local teachers have attended six-hour long workshops for two consecutive days. The workshops take place during the school term and at a local university, so the teachers have to be away from their classes during this time and their schools need to cover the costs of substitute teachers. Consequently, we plan many of the sessions prior to the workshop, in order to make the best use of the time we have with the teachers, and this planning has often resulted in activities that do give learners specific direction. We are aware of approaches to PD that solely involve self-directed, constructionist activities, such as the four-day Constructing Modern Knowledge workshops run by Martinez and Stager (2013). However, we have typically had 1-2 instructors during the workshops, which would have made it difficult to provide guidance to 20-30 teachers working on openended projects, and the two days has not been enough time to cover essential CK and to also run design activities. There are also difficulties that are discussed in the tension between expert and novice and tension between actual and aspirational sections, which prevent us from only including self-directed, constructionist sessions in our PD. To address this tension, we intend to run after-school sessions over a term in our PD. This structure would allow teachers to work on design projects during their free time and for us to provide guidance during the sessions or through email. 


\section{Tension between Individual and Group}

The tension between individual and group refers to the challenge of facilitating productive collaboration between the teachers that attend the PD. As Brennan (2015) argues, learners should be encouraged to connect with each other and learners working in groups can learn new perspectives from one another. We have not had to negotiate this tension to the same extent as Brennan, which could be due to the collaborative and face-to-face nature of our workshops. There are a few aspects of our workshops that allow for collaboration to occur with minimal intervention from us, such as introduction sections, meal breaks, and collaborative hands-on or lesson planning activities.

One challenge, that we consider to be part of the tension between individual and group, is the sustaining of knowledge sharing and connections after the PD has been completed. Unlike the ScratchEd model, we do not have an online community for our PD for teachers to share resources or discuss ideas in. Additionally, teachers that have attended the workshops have usually been from different schools and it has been rare for more than two teachers from the same school to attend the same workshop. To help address this challenge, we decided to design a workshop in 2018 that is focused on assisting experienced C\&CT teachers acquire the CK and PCK they need to establish local professional learning communities (PLCs).

\section{Tension between Expert and Novice}

The tension between expert and novice refers to the tension between the teachers who are considered to be knowledgeable about the content in the PD activities (the experts) and the teachers who have only begun to learn the content (the novices). Like Brennan (2015), the teachers that have attended our PD have had a wide range of CK and experience teaching C\&CT. Some of the teachers that have attended our PD were professional software developers before their teaching careers, whereas some other teachers had not learned anything about C\&CT prior to our PD. However, the ways in which we have experienced this tension seem to differ from Brennan (2015), which could also be due to the differences in the PD format. Brennan (2015) gave examples that were mainly experienced in the interactions between the teachers when they were learning together. On the other hand, we ourselves have experienced this tension when trying to choose planned learning outcomes, session themes and activities that are appropriate for teachers that have varying levels of CK and PCK.

We consider the difficulty of providing resources and instruction that are suitable for a wide range of teachers' CK to be encompassed by the tension between expert and novice. We have encountered this difficulty since our first PD in 2013 and, consequently, negotiating this tension has been the precursor to several of the major changes we have made to our PD. For example, prior to 2015 we had only run one workshop per year, with activities that involved high school Digital Technologies concepts. However, in 2015, we decided to run two different workshops, the Introductory and Advanced workshops, which had activities that were designed to cater for teachers with different levels of CT 
CK. This decision was a result of reflecting on our observations of teachers' varying levels of CK and responses to the feedback surveys in the previous years' workshops. We have also given the teachers the choice to participate in different activities that are suitable to their level of expertise, which are similar to the breakout sessions in the Meetups described by Brennan. For example, in the 2016 High School workshop, teachers chose between a session that introduced the teaching of Data Science in $\mathrm{R}$ and an Introduction to General-Purpose Programming with Sonic Pi.

As we have often presented short talks before the activities in each PD session, we have often been positioned as the experts during the PD. However, some of the teachers have had expertise in areas of CK and PCK that we did not have. Consequently, we have invited some teachers to assist us when running activities or present their own sessions, and also encouraged the expert teachers to share their knowledge with the rest of the group during the PD. For example, in the 2017 Primary School workshop we invited a teacher that had attended a workshop in an earlier year, to help us run a Collaborative Lesson Planning Activity. That teacher had extensive knowledge about relevant K-6 curriculum outcomes, that we did not have ourselves, and consequently was able to help the teachers map their lesson plans to these outcomes.

We have also encountered the tension between expert and novice when we have considered the changes to make to the PD from teachers' suggestions in the feedback surveys. Although we have run workshops that have had activities that aim to cater for different levels of teachers' $\mathrm{CK}$, we still have received feedback that indicated we may have needed to differentiate the content more. An example of this was found in the feedback responses of the 2017 Maths workshop, which was intended to be suitable for teachers with some CK and some experience Coding in a Blocks-based language, like Scratch. One teacher stated that the workshop content was "All well delivered and at right level", whereas another teacher responded that "As a beginner of coding, I found the pace of the coding activities too fast." Despite the changes we have made to the PD to address the challenge of differentiation, negotiating this tension seems to be inevitable, as the teachers that have attended the PD have always had a wide range of CK. As discussed in the tension between anthropology and assessment section, one way to address this would be to measure the teachers' CK before the PD, which could help us plan sessions that are appropriate for teachers with different levels of CK.

\section{Tension between Actual and Aspirational}

The tension between actual and aspirational refers to the difficulty of providing constructionist learning experiences to teachers that they can replicate in their classes. Brennan (2015, p. 295) argues that "constructionist learning experiences are fundamentally at odds with the lived reality of K-12 education" in many ways. However, we contend that teachers that have attended our PD would be able to incorporate some constructionist learning experiences into their classes, particularly in view of the emphasis that creative thinking has in the general capabilities of the Australian Curriculum (ACARA, 2018). 
Unlike Brennan (2015), the changes to our PD have been largely been motivated by the challenges reported by the teachers, which would be considered to be on the actual side of the tension between actual and aspirational. The feedback from the teachers in our workshop surveys, particularly those in 2013 and 2014, indicated that the teachers wanted resources that could be directly used in their classes, such as lesson plans. Furthermore, the current consensus is that PD is effective when it is aligned with the needs of the participating schools and involves collaboration with school administration (Desimone, 2009; Menekse, 2015). Therefore, we have often designed PD which has addressed the actual nature of K-12 education, rather than the aspirational nature of a more constructionist approach.

In recent workshops, we have also included sessions that involved open-ended, constructionist learning experiences such as the Creative Computing session in the 2017 Primary workshop. Although there is a climate of high-stakes testing in Australia, there are ways to introduce design activities that align with outcomes in the relevant curricula. For example, our local state education authority states that, "Designing, making, data collection and analysis" are part of the Science and Technology subject area (NSW Education Standards Authority, 2018). Additionally, in the national curriculum there are general abilities, such as Critical and Creative Thinking (ACARA, 2018), which could be addressed through the inclusion of design activities in teachers' classes.

One of the other challenges that we consider to be part of the tension between actual and aspirational is related to the inclusion of C\&CT into a curriculum that is overcrowded (Polesel, Rice, \& Dulfer, 2014). Ideally, teachers would have sufficient time to learn and teach $\mathrm{C} \& \mathrm{CT}$ in addition to other subjects, but it is challenging for teachers to find this time. To address this challenge, local educational authorities and researchers have recommended that teachers find ways to integrate C\&CT across existing subject areas (Barr \& Stephenson, 2011; NSW Education Standards Authority, 2018). One way we have found to negotiate this tension is the creation, in 2017, of two workshops that were focussed on integrating C\&CT with mathematics: ScratchMaths for Primary School teachers and Networks for High School mathematics teachers. The contents of these workshops were aligned with specific curriculum outcomes, from mathematics and $\mathrm{C} \& \mathrm{CT}$.

\section{Tension between Anthropology and Assessment}

One of the tensions that we have experienced, which was not identified by Brennan (2015), is the tension between assessing the teachers' CK and PCK and restricting our evaluation to quality assurance and self-reported measures of self-efficacy or impact. Brennan (2015, p. 295) does not mention the assessment of the teachers during the ScratchEd PD directly but does state that there is a "lack of meaningful metrics for assessment and evaluation" when defining the tension between actual and aspirational. However, we contend that there are metrics for assessment of CK and PCK that can be meaningful and appropriate for suitable contexts and, consequently, we consider the tension between anthropology and assessment as separate to the tension between actual 
and aspirational (see Fig. 3). We also recognise that the formats of different PD in the ScratchEd PD may be more difficult to assess than workshops. For example, it could be impractical to assess teachers' CK and PCK before and after a breakout session in one of the ScratchEd Meetups.

Although the teachers that have participated in our PD have not suggested that we include assessment, we contend that there are two main reasons why a more rigorous evaluation of CK and PCK would be beneficial. Firstly, in order to improve the effectiveness of our PD, we need to know whether we have had a positive effect on teachers' CK and PCK. Presently, we base improvements to our activities based on self-reported measures given by participating teachers. Secondly, organisations and governments spend significant funds on PD and, consequently, there is a need to identify whether the PD has had a positive impact on teachers' classroom practices beyond teachers self-reporting. For example, researchers from Google, who have funded the CS4HS (Computer Science 4 High School) program, have recently begun investigating the long-term impacts of their programs on teachers' self-reported knowledge of C\&CT and their beliefs about teaching C\&CT (Ravitz, Stephenson, Parker, \& Blazevski, 2017).

One of the challenges that we have encountered, that we consider part of the tension between anthropology and assessment, is the difficulty of identifying appropriate instruments to measure teachers' CK and PCK. There have been instruments developed for assessing understanding of $\mathrm{CK}$, but much of this work has been done in tertiary education (Guzdial, 2015), and these instruments may not be appropriate for measuring the CK that K-12 teachers need. In his review of PD studies conducted in the United States of America between 2004 and 2014, Menekse (2015) reports that seven of the studies involved some assessment of teachers CK. However, a deeper reading of these studies uncovered that only three of them involved measurement of CK that was not self-reported. Furthermore, these three studies used instruments that were developed by the authors or by an unidentified source, and did not report reliability of scales. There is also currently limited research into the assessment of PCK specific to C\&CT (Saeli

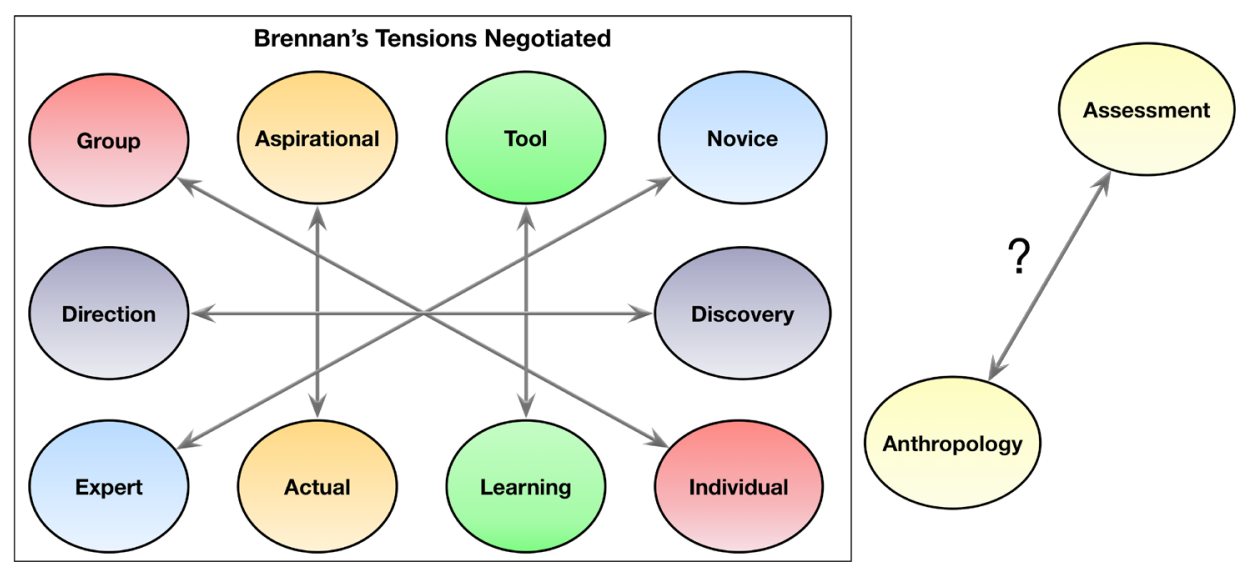

Fig. 3: Tension between anthropology and assessment. 
et al., 2011; Yadav et al., 2018). A form of PCK, which is referred to as Computational Pedagogical Content Knowledge (CPACK), was present in one of the studies reviewed by Menekse (2015). However, in the study in which Yasar and Veronesi (2015) introduce CPACK, they do not report measures of teachers' CPACK or include details on how data can be collected or analysed to measure teachers' CPACK. Similarly, while the research conducted by Yadav et al. (2018) examines teachers' PCK through teaching vignettes, their methods do not include quantitative measures.

\section{Discussion and Further Research}

In this paper, we have analysed our PD through the framework of the 'tensions negotiated' defined by Brennan (2015). In this section, we summarise our findings and discuss the implications for PD design. We also outline our plans for future research.

To negotiate the tension between tool and learning we have found it is helpful to include a balance of activities that address both tools and learning, as we recognise that both CK and PCK are essential. We have also identified potential technical issues that can be encountered when using the different tools, and believe it is important that teachers are made aware of these issues.

To negotiate the tension between direction and discovery we have observed it is valuable to include activities where teachers can explore concepts without direct instruction from a resource or instructor, such as the 10 Blocks activity. We have also found that it is beneficial to provide teachers with choices of activities in the form of parallel sessions, or to let them choose their own direction for learning and then offer instructional support. In response to survey feedback, we have included sessions where teachers worked together to create an artefact unaided, such as a unit plan, or sessions where teachers were given a problem to solve with minimal guidance. These sessions were very well received in subsequent years.

To negotiate the tension between individual and group we have included an increasing number of collaborative activities, such as collaborative lesson planning and problem solving. For our PD design for 2018, we have planned to train and support teachers who are interested in establishing PLCs. These PLCs could encourage the sharing of knowledge and collaboration between teachers after they have participated in the PD. The development of the workshop was influenced by the work to develop Master Teachers in England (Sentance et al., 2014).

To negotiate the tension between expert and novice we observed that it is useful to design extension activities for the teachers that complete the PD activities quickly. We have differentiated the activities to cater for different levels of CK within workshops and created different workshops to accommodate different PCK needs according to the level of schooling that participants teach at. We also found that inviting expert teachers to share their experiences implementing C\&CT with their classes was highly regarded by all participating teachers.

To negotiate the tension between the actual and aspirational we have started running workshops that address existing subject areas and specific curriculum outcomes. 
It is assumed that the teachers participating in these workshops already have subject knowledge in that domain, and that they would be able to assess those subjects already. These workshops are narrower in scope but provide greater depth of learning. We have made changes to the PD that are intended to address the aspirational aspects of constructionism as well. We have found these changes have provided teachers with skills and resources that can help them introduce design activities to their classes, such as the Creative Computing curriculum guide (Brennan et al., 2014). Another PD project planned for 2018, which may address this tension, involves running the PD over a longer period of time. This could allow for longer-term open-ended projects that teachers can, in turn, develop with their students.

The new identified tension, the tension between anthropology and assessment, extends the tensions negotiated by Brennan (2015). Although there are arguments for measuring outcomes in our PD, as explained in the previous section, it could also be argued that PD with constructionism as a framework for action should not involve any assessment of learning outcomes. Papert and the MIT Logo group were known for being opposed to standardised testing (Agalianos et al., 2006), and Papert (1987) argued that focusing on assessing outcomes could lead to technocentrism. However, there are examples of constructionist research that involve the collection of quantitative measurable learning outcomes, including the study of children designing instructional mathematics games conducted by Harel and Papert (1990). Harel and Papert (1990, p. 10) referred to these outcomes as "thinner results" because, while they could be used to assess the students' performance, they are not as in-depth and rich as the qualitative data collected in the study. While we agree with this sentiment, the analysis of quantitative data helps us understand what we can do to improve our PD. Furthermore, the reporting of quantifiable measures helps address the concerns of funding agencies and government bodies regarding the impact of our PD on teachers.

We believe that learners, whether they are teachers or students, should be encouraged to explore ideas through the self-directed creation of artefacts that are personally meaningful to them. However, as Noss and Hoyles (1996) argue, this does not mean that we should not plan for learning outcomes or that there should be no assessment of these outcomes. Thus, we need to negotiate the tension between acting as anthropologists and assessing teachers' learning in CK and PCK with quantitative measures. Our next PD workshops will integrate our desire for authentic constructionist experiences and the desire to improve these experiences by ensuring that the PD has had a measurable positive effect on teachers' CK and PCK.

\section{Acknowledgements}

The authors would like to thank Google Inc. for funding the CS4HS workshops held at our institution. We would also like to thank the university academics who presented talks and gave laboratory tours during the workshops, as well as the administrative staff of our institution. 


\section{References}

ACARA. (2018). F-10 Curriculum - General Capabilities. from https://www.australiancurriculum.edu.au/f-10-curriculum/general-capabilities/

Agalianos, A., Whitty, G., Noss, R. (2006). The Social Shaping of Logo. Social Studies of Science, 36(2), 241-267.

Angeli, C., Voogt, J., Fluck, A., Webb, M., Cox, M., Malyn-Smith, J., Zagami, J. (2016). A K-6 computational thinking curriculum framework: implications for teacher knowledge. Journal of Educational Technology \& Society, 19(3), 47.

Barr, V., Stephenson, C. (2011). Bringing computational thinking to K-12: what is Involved and what is the role of the computer science education community? ACM Inroads, 2(1), 48-54.

Blikstein, P. (2013). Digital fabrication and 'making'in education: The democratization of invention. FabLabs: Of machines, makers and inventors, 1-21.

Brennan, K. (2015). Beyond Technocentrism: Supporting Constructionism in the Classroom. Constructivist Foundations, 10(3), 289-296.

Brennan, K., Balch, C., Chung, M. (2014). Creative Computing - Scratch Ed. Retrieved March 2018, from http://scratched.gse.harvard.edu/guide/

Brennan, K., Resnick, M. (2012). New frameworks for studying and assessing the development of computational thinking. Paper presented at the Proceedings of the 2012 annual meeting of the American Educational Research Association, Vancouver, Canada.

Brown, Q., Briggs, A. (2015). The CS10K initiative: progress in K-12 through "exploring computer science" part 1. ACM Inroads, 6(3), 52-53.

Cooper, S., Grover, S., Guzdial, M., Simon, B. (2014). A future for computing education research. Communications of the ACM, 57(11), 34-36.

Desimone, L.M. (2009). Improving Impact Studies of Teachers' Professional Development: Toward Better Conceptualizations and Measures. Educational Researcher, 38(3), 181-199.

DiSessa, A.A., Cobb, P. (2004). Ontological innovation and the role of theory in design experiments. The journal of the learning sciences, 13(1), 77-103.

Falkner, K., Vivian, R., Falkner, N., Williams, S.-A. (2017). Reflecting on Three Offerings of a CommunityCentric MOOC for K-6 Computer Science Teachers. Paper presented at the Proceedings of the 2017 ACM SIGCSE Technical Symposium on Computer Science Education, Seattle, Washington, USA.

Fisher, L.M. (2016). A decade of ACM efforts contribute to computer science for all. Communications of the ACM, 59(4), 25-27.

Garneli, V., Giannakos, M.N., Chorianopoulos, K. (2015, 18-20 March 2015). Computing education in K-12 schools: A review of the literature. Paper presented at the 2015 IEEE Global Engineering Education Conference (EDUCON).

Guzdial, M. (2015). Learner-centered design of computing education: Research on computing for everyone. Synthesis Lectures on Human-Centered Informatics, 8(6), 1-165.

Harel, I., Papert, S. (1990). Software design as a learning environment. Interactive learning environments, 1(1), 1-32.

Kafai, Y.B., Burke, Q. (2013). Computer programming goes back to school. Education Week, 61-65.

Martinez, S.L., Stager, G. (2013). Invent to learn: Making, tinkering, and engineering in the classroom: Constructing modern knowledge press Torrance, CA.

Menekse, M. (2015). Computer science teacher professional development in the United States: a review of studies published between 2004 and 2014. Computer Science Education, 25(4), 325-350.

Noss, R., Hoyles, C. (1996). Windows on mathematical meanings: Learning cultures and computers (Vol. 17): Springer Science \& Business Media.

NSW Education Standards Authority. (2018). Digital Technologies and ICT Resources. Retrieved 11 March 2018, from http://educationstandards.nsw.edu.au/wps/portal/nesa/k-10/learning-areas/technologies/coding-across-the-curriculum

Papert, S. (1980). Mindstorms: Children, computers, and powerful ideas: Basic Books, Inc.

Papert, S. (1987). Information Technology and Education: Computer Criticism vs. Technocentric Thinking. Educational Researcher, 16(1), 22-30.

Papert, S. (2000). What's the big idea? Toward a pedagogy of idea power. IBM Systems Journal, 39(3/4), 720.

Polesel, J., Rice, S., Dulfer, N. (2014). The impact of high-stakes testing on curriculum and pedagogy: A teacher perspective from Australia. Journal of Education Policy, 29(5), 640-657. 
Prieto-Rodriguez, E., Hickmott, D. (2016). Preparing teachers for the Digital Technologies curriculum: preliminary results of a pilot study. Paper presented at the Constructionism 2016 Conference, Bangkok, Thailand.

Ravitz, J., Stephenson, C., Parker, K., Blazevski, J. (2017). Early Lessons from Evaluation of Computer Science Teacher Professional Development in Google's CS4HS Program. ACM Trans. Comput. Educ., 17(4), $1-16$.

Resnick, M. (2017). Fulfilling Papert's Dream: Computational Fluency for All. Paper presented at the Proceedings of the 2017 ACM SIGCSE Technical Symposium on Computer Science Education, Seattle, Washington, USA.

Saeli, M., Perrenet, J., Jochems, W.M., Zwaneveld, B. (2011). Teaching programming in secondary school: a pedagogical content knowledge perspective. Informatics in Education, 10(1).

Sentance, S., Csizmadia, A. (2016). Computing in the curriculum: Challenges and strategies from a teacher's perspective. Education and Information Technologies, 1-27.

Sentance, S., Csizmadia, A. (2017). Professional Recognition Matters: Certification for In-service Computer Science Teachers. Paper presented at the Proceedings of the 2017 ACM SIGCSE Technical Symposium on Computer Science Education.

Sentance, S., Humphreys, S., Dorling, M. (2014). The network of teaching excellence in computer science and master teachers. Paper presented at the Proceedings of the 9th Workshop in Primary and Secondary Computing Education, Berlin, Germany.

Shulman, L.S. (1986). Those Who Understand: Knowledge Growth in Teaching. Educational Researcher, 15(2), 4-14.

Webb, M., Davis, N., Bell, T., Katz, Y.J., Reynolds, N., Chambers, D.P., Sysło, M.M. (2016). Computer science in K-12 school curricula of the 21st century: Why, what and when? Education and Information Technologies, 1-24.

Yadav, A., Sands, P., Good, J., Lishinki, A. (2018). Computer Science and Computational Thinking in the Curriculum: Research and Practice. In J. Voogt, G. Knezek, R. Christensen, \& K.-W. Lai (Eds.), Handbook of Information Technology in Primary and Secondary Education (pp. 1-18). Cham: Springer International Publishing.

Yasar, O., Veronesi, P. (2015). Computational Pedagogical Content Knowledge (CPACK): Integrating Modeling and Simulation Technology into STEM Teacher Education. Paper presented at the Society for Information Technology \& Teacher Education International Conference 2015, Las Vegas, NV, United States.

D. Hickmott is a PhD candidate and Research Assistant in the School of Education at the University of Newcastle, Australia. His research interests include the integration of digital technologies in K-12 education and professional learning, with a particular focus on: approaches for supporting teachers learning coding and computational thinking, and the development and evaluation of serious games for learning. His doctoral research is focused on understanding how K-6 teachers integrate coding into the broader primary school curricula.

E. Prieto-Rodriguez holds a Bachelor degree in Mathematics and $\mathrm{PhD}$ in Theoretical Computer Science. From 2005, she has worked extensively in STEM education, including several Australia-wide research projects. She is currently engaged in several projects focused on the use of technology for the learning of mathematics and mathematics teacher training and professional development. She is a member of the University of Newcastle Teachers and Teaching Research Centre where she leads the Mathematics Education Group. 